Proceedings

\title{
Good Things Come in Larger Packages: Size Matters in Neotropical Fruit-Feeding Butterfly Dispersal ${ }^{\dagger}$
}

\author{
Geraldo B. Freire, Jr. ${ }^{1, *}$, Hernani Oliveira ${ }^{2}$, Thayane Silva ${ }^{1}$, Hanna Pamela ${ }^{1}$, Joao P. Dias ${ }^{1}$, Jessie P. Santos ${ }^{3}$, \\ Onildo J. Marini-Filho ${ }^{4}$, André V.L. Freitas ${ }^{3}$ and Ivone R. Diniz ${ }^{1}$
}

Citation: Freire, G.B., Jr.; Oliveira, H.; Silva, T.; Pamela, H.; Dias, J.P.; Santos, J.P.; Marini-Filho, O.J.;

André V.L. Freitas; Diniz, I.R. Good Things Come in Larger Packages: Size Matters in Neotropical Fruit-Feeding Butterfly Dispersal. 2021, 68, x.

https://doi.org/10.3390/xxxxx

Published: date

Publisher's Note: MDPI stays neutral with regard to jurisdictional claims in published maps and institutional affiliations.

Copyright: (C) 2021 by the authors. Submitted for possible open access publication under the terms and conditions of the Creative Commons Attribution (CC BY) license (http://creativecommons.org/licenses /by/4.0/).
1 Universidade de Brasília-UnB, Brasília, DF, Brazil

2 Universidade of Paraná-UFPR, Curitiba, PR, Brazil

3 Universidade Estadual de Campinas-UNICAMP, Campinas, SP, Brazil

4 Instituto Chico Mendes de Conservação da Biodiversidade-ICMBio, Brasília, DF, Brazil

* Correspondence: geraldo.bfreire82@gmail.com; Tel.: +55-(61)-99813-1982

† Presented at the 1st International Electronic Conference on Biological Diversity, Ecology and Evolution, 1531 March 2021; Available online: https://bdee2021.sciforum.net/.

\begin{abstract}
Body size correlates to many aspects of a species' natural history, such as life span, abundance, and dispersal capacity. However, contrasting trends have been reported for the relationship between body size and these ecological traits. We have marked and recaptured 539 individuals from 27 species of fruit-feeding butterflies to study how body size affect species abundances, dispersal, and detectability in a Neotropical savanna (Cerrado). Body size has shown to be an efficient predictor of abundance, however this association was not significant after phylogeny was taken into account. Moreover, body size has positively influenced the dispersal rate, distance, and individual detectability, indicating that larger butterflies have a greater proportion of dispersing individuals over longer distances, and were detected through longer periods, than their smaller relatives. Large butterflies demand more resources, which may be forcing them to disperse in search for better habitats. On the other hand, smaller species may be better able to survive in small patches, which is explained by their lower dispersal ability. Nevertheless, their lower dispersal ability, if not compensated by large population sizes, may threaten the small-bodied species inhabiting environments with intense deforestation rates, such as the Cerrado. Finally, our study highlights the importance to consider species evolutionary history in order to study complex trait-environment relationships.
\end{abstract}

Keywords: Body-size; Cerrado; evolutionary history; Nymphalidae; species traits

\section{Introduction}

Dispersal is a key process for species survival and persistence under those environmental changes that require a spatial response of populations, such as to keep track of a shifting climatic niche or to maintain connections among populations in increasingly fragmented landscapes [1]. Accordingly, an increasing effort has been made to understand the conditions and contexts that modulate the dispersal expression [2]. Identifying which life history traits co-vary with dispersal related traits will enable us to make predictions about species responses in the face of environmental changes [3,4]. This is particularly relevant for species inhabiting environments with high deforestation rates, such as the Neotropical Savannah known as the Cerrado [2,5].

Body size is a morphological trait related to many aspects of species natural history, such as life span, abundance, and dispersal ability [6-9]. Since body size is strongly associated with metabolism and resource use [6], its relationship with the species abundance can also reveal how resources are partitioned into ecological systems [10,11]. In fruit-feeding butterflies (Nymphalidae), some evidences suggest larger butterflies as less abundant and with lower dispersal ability, thus more vulnerable to habitat loss compared to their 
smaller relatives $[12,13]$. Contrastingly, other studies have shown that larger butterflies have higher dispersal ability, which can be an advantage to reach and colonize new habitats patches, compared to their smaller relatives $[13,14]$. Although the interplay between body size, abundance, and dispersal still not fully understood, it suggests a trade-off between reproductive capacity and dispersal ability $[2,14]$.

As deforestation increases, the connectivity between forest patches is decreased, which in turn can affect the ability of a species to disperse and to colonize new habitats $[4,7]$. However, trait-environmental relationships may not be exclusively explained by current ecological processes but can also reflect the evolutionary history shared by different species in ecological communities $[15,16]$. Thus, the phylogenetic information, especially when combined with both ecological and functional methods is essential for a more accurate understanding about community assembly [4,17]. The evaluation of phylogenetic signal strength on butterfly traits has been recently incorporated to disentangle butterfly assemblies along spatial gradients in the Amazon forest $[4,18]$. Nevertheless, this approach remains understudied to unveil the influence of body size on abundance and dispersal ability for most insect populations, particularly in the Cerrado.

Using the fruit-feeding butterfly (Nymphalidae), we herein describe the populations parameters of different species in the Cerrado, and addressed the following questions: (1) How does the body size affect the abundance, dispersal rate and distance, and detectability of different fruit-feeding butterflies species? Considering the strong association between body size and metabolism, plus the tradeoff between reproductive capacity and dispersal ability [2], we expect that larger butterflies would be less abundant but with greater dispersal capacity when compared with their smaller relatives $[7,8]$; (2) How phylogeny mediates the association between body size, abundance, and dispersal of these butterflies? Body size is a highly conserved trait in the fruit-feeding butterfly guild $[4,15]$. Thus, we expect at least an indirect effect of phylogeny on dispersal ability, but not in species abundance, since this trait is generally defined by a complex interaction of many environmental factors [19-21].

Our findings will allow for a better understanding of how species mobility is related to body size and phylogeny in fruit-feeding butterflies in the Cerrado, where the knowledge about butterflies' dispersal is incipient [7]. In addition, the results will also be able to be used as a tool to evaluate the local extinction risk and to foster better plans to protect the biodiversity in the face of the current deforestation rates in the Cerrado [22,23].

\section{Experiments}

\subsection{Study Site}

An intensive butterfly survey was conducted during 35 consecutive days in 2013 (11 February to $17 \mathrm{March}$ ) in Fazenda Água Limpa (4500 ha). This period corresponds to the end of the rainy season in the Cerrado [21]. The study site is inside a protected area embracing 10,000 ha [23] near Brasilia, DF, Brazil (Figure 1). This period was chosen in order to optimize the sampling effort, it has been used as baseline a previous report for these butterflies in the Cerrado [20].

A grid of 1.8 ha $(150 \times 120 \mathrm{~m})$ with four linear transections (P1-P4) was set up in savannah-gallery forest ecotone. These transections were $40 \mathrm{~m}$ apart from each other. Six Van Someren-Rydon "bait-traps" (30 m apart) were equally distributed from savannah through gallery forest in each linear transection (Figure 1). Thus, 24 bait-traps were used in the present study. A mixture prepared with bananas and sugarcane $(\sim 50 \mathrm{~mL})$ was fermented for $48 \mathrm{~h}$ and added to each bait-trap, following an established sampling protocol for these butterflies [25]. Using a permanent ink pen, we have marked all captured butterflies, which received an individual number at the ventral side of the forewing. After marked, they were released, and the subsequent recaptures were recorded. 


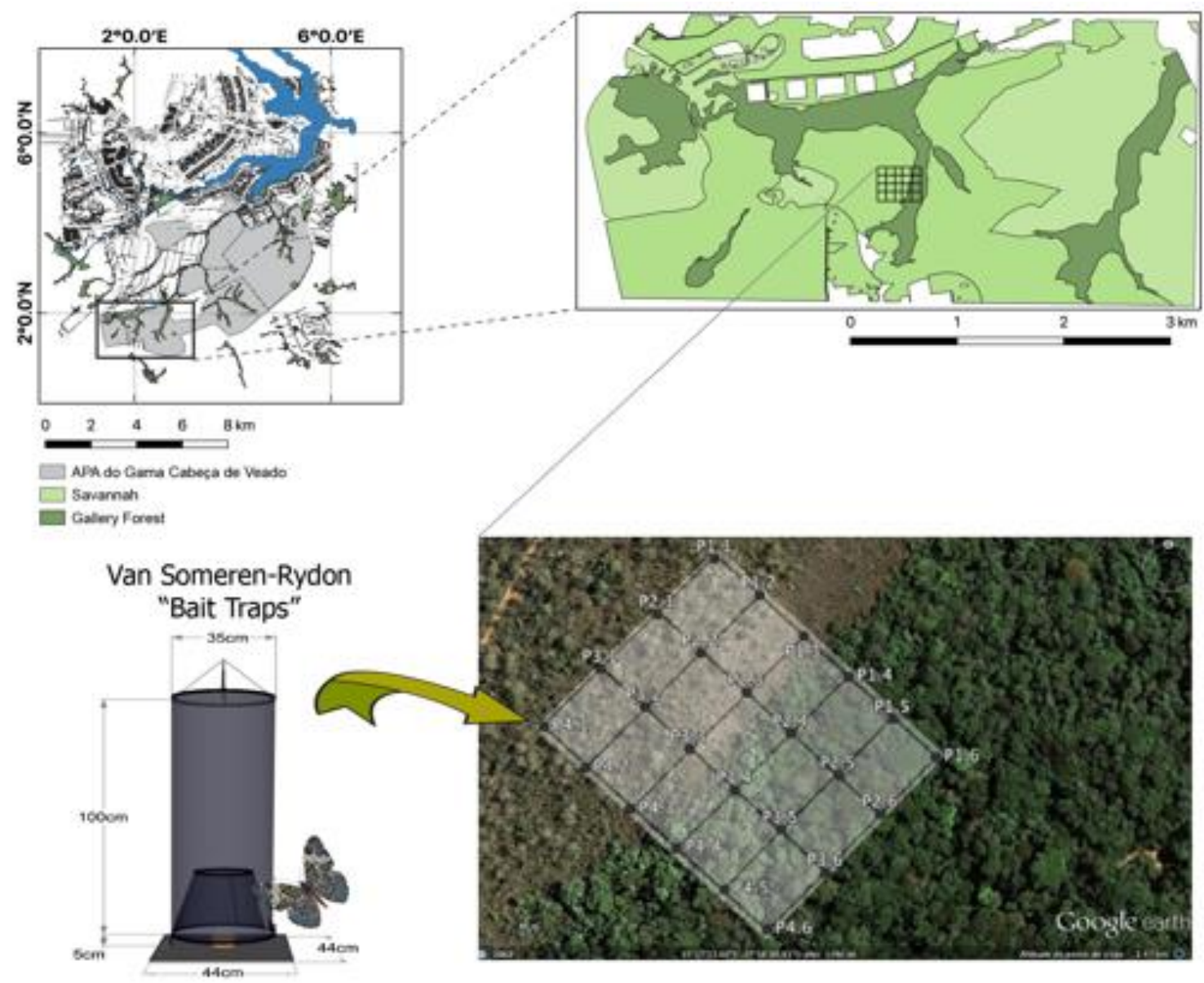

Figure 1. Experimental grid of 1.8 ha (150 vs. 120 m) installed in Fazenda Água Limpa located at “APA do Gama Cabeça de Veado" a 10,000 ha of protected area near Brasília-DF, Brazil.

\subsection{Fruit Feeding Butterflies}

Fruit-feeding butterflies (Nymphalidae) use rotting fruit as their major food resource [25]. They comprise about $50-75 \%$ of all Neotropical species richness in this family ( 6000 spp) [26], are easily sampled with a standardized trap protocol and respond to environmental changes in space and time [25]. Moreover, their life-history traits and morphology are well studied. For these reasons, fruit-feeding butterflies are well suited for quantitative studies of dispersal, and are excellent model organisms for studies in ecology and evolution $[2,25]$.

\subsection{Phylogenetic, Morphological and Ecological Traits}

The phylogenetic relationships of fruit-feeding butterflies were estimated using the $\mathrm{R}$ package phytools [27]. Species divergence time was estimated based on the Nymphalid family tree [28]. The branches of the original tree belonging to absent species in our community were pruned. To include species of our community that are absent in the original tree, we consulted the topologies from the specific taxonomy literature and specialists (Freitas, pers. comm.). The length of the new branches created by the insertion of these species was determined as the half of branch lengths from the same node on the original tree.

We considered forewing length $(\mathrm{mm})$ as surrogate for body size, once the correlation between wingspan and body length is about 0.8 in fruit-feeding butterflies [13]. Ten specimens of each species were measured using ImageJ software [29].

The following variables were considered the for each species: (a) relative abundance (n): number of individuals captured in each species; (b) dispersal distance (m): cumulative 
distance dispersed by each individual through the sampling period; (c) dispersal rate (\%): proportion of dispersing individuals for each species; (d) detectability (days): period of time between the first and the last capture recorded for each individual in the study site. The dispersal distances were calculated based on the lower distance between two or more traps visited by each individual, and were measured using the "ruler" tool of the Google Earth software.

\subsection{Statistical Analysis}

We performed phylogenetic independent contrasts (PIC) and estimated the phylogenetic signal for body size, abundance, dispersal distance and rates, and detectability $[30,31]$. Then we estimated the correlation between all sets of PICs using linear regression through the origin [32]. The significance of all regression were tested using permutational methods because the conventional method based on a F-distribution is biased for regressions through the origin [33]. All phylogenetic analyses were performed using the R software packages: ape, picante, phytools [34,35].

\section{Results}

A total of 539 individuals belonging to 13 genera and 27 species of Nymphalidae were captured, with 190 recaptures, and a 30\% recapture rate. Pareuptychia ocirrhoe (Fabricius, 1776) $(\mathrm{N}=174)$, Hamadryas feronia (Linnaeus, 1758) $(\mathrm{N}=70)$, and Paryphthimoides phronius (Godart, [1824]) $(\mathrm{N}=47)$ were the most abundant species, while nine species $(40 \%)$ were represented by less than five individuals each (Appendix A). Satyrini $(\mathrm{N}=374 ; 59 \%)$, and Biblidinae $(\mathrm{N}=179 ; 28 \%)$ were the most abundant clades, whereas Charaxinae $(\mathrm{N}=$ $13,2 \%)$, and Nymphalinae ( $\mathrm{N}=14 ; 2 \%)$ were those with lower abundance.

Satyrini was the clade composed by the smaller species, while Brassolini and Morphini had larger bodied species (Appendix A). Considering all the measured traits, only the body size was associated with the evolutionary history shared by these butterfly's species (Table 1), it means a trait conservatism where close lineages have similar body sizes. It was observed a significant negative relationship between body size and abundance $(\beta=-1.7 ; p=0.02)$. Nevertheless, the size-abundance association was non-significant while the phylogenetic non-independence was taken into account $(\beta=-0.09 ; p=0.76)$.

Considering the dispersal rates, Paryphthimoides poltys (13\%), P. phronius and Pareuptychia ocirrhoe (16\%) were the species with lowest values, whereas Zaretis isidora (66\%), Eryphanis automedon (60\%), and Memphis moruus (50\%) were those with greater proportion of population had dispersed (Appendix A). Charaxinae (55\%) and Brassolinae (37\%) were the clades with higher dispersal rates, while Satyrinae $(15 \%)$ had the lowest dispersal rate. From the recaptured individuals, $88(60 \%)$ dispersed through short distances $(0-70 \mathrm{~m})$, while $41(27 \%)$ dispersed intermediary distances (71-141 m), and 18 (13\%) dispersed long distances (142-422 m). The shortest distances were dispersed by Callicore sorana $(24.6 \mathrm{~m})$, Opsiphanes invirae ( $30 \mathrm{~m})$, and Pareuptychia ocirrhoe $(41 \mathrm{~m})$, while the longest distances were recorded in Eryphanis automedon, Catonephele acontius and Paryphthimoides phronius (Appendix A).

Individuals of Catonephele acontius, Hamadryas feronia, and Hamadryas februa have been detected through longer periods in the study site (6.3, 5.5, 5.5 days, respectively), while Yphthimoides renata, Zaretis isidora, and Taygetis laches were those with the shortests periods between the first and the last capture in the study site (2.1, 2.3, 2.5 days, respectively) (Appendix A). The PICs analyses indicate body size has positively influenced the dispersal rate (Figure 2a), distance (Figure 2b), and individual detectability (Figure 2c), indicating that larger butterflies have a greater proportion of dispersing individuals over longer distances, and were detected through longer periods, than their smaller relatives (Table 2). 
Table 1. Phylogenetic signal values (Blomberg's K and P-value) of the species-traits measured in fruit feeding butterflies captured in Fazenda Água Limpa, Brasília, Brazil.

\begin{tabular}{cccc}
\hline Traits & Blomberg's K & $p$-Value & \\
\hline Body size & 1.1 & 0.001 & $* * *$ \\
Dispersal rate & 0.76 & 0.07 & $\mathrm{~ns}$ \\
Dispersal distance & 0.53 & 0.53 & $\mathrm{~ns}$ \\
Detectability (days) & 0.39 & 0.78 & $\mathrm{~ns}$ \\
Abundance & 0.47 & 0.72 & $\mathrm{~ns}$ \\
\hline
\end{tabular}

$\left({ }^{* * *}\right)$ Indicates $p \leq 0.001 ;(\mathrm{ns})$ indicates non-significant.

Table 2. Phylogenetic Independent Contrasts (PICs) between body size and other species traits in fruit feeding butterflies captured in Fazenda Água Limpa, Brasília, Brazil.

\begin{tabular}{cccc}
\hline Traits & Beta & $p$-Value & \\
\hline Dispersal rate & 1.07 & 0.01 & $* *$ \\
Dispersal distance & 4.25 & 0.005 & $* *$ \\
Detectability (days) & 0.13 & 0.04 & $*$ \\
Abundance & -0.09 & 0.76 & $\mathrm{~ns}$ \\
\hline
\end{tabular}

$\left(^{*}\right)$ Indicates $p \leq 0.05 ;\left(^{* *}\right) p \leq 0.01 ;($ ns) indicates non-significant.

\section{Discussion}

\subsection{Sampling Design}

The present study was performed in 35 consecutive days, which partially overlapped the peak of fruit-feeding butterflies in the Cerrado [21]. Moreover, the sampling design accounted for 28 bait-traps installed in a relatively small area (1.8 ha.), these both factors altogether probably had reflected in the higher abundance, species richness, and mainly the recapture rates $(30 \%)$ compared to another study performed at Serra da Canastra National Park, which sucessfuly reported seven percent of recaptures [7].

\subsection{Trait-Dispersal Relationships}

A clear phylogenetic signal was found in body size, indicating trait conservatism where close lineages have similar body sizes [4,15]. Moreover, were have observed divergent results while considering phylogenetic non-independence in trait-dispersal relationships in these butterflies. Thus, both factors highlights the importance to consider species evolutionary history in order to study complex trait-environment relationships.

Charaxinae species have a large mass of flight muscles, and they are excelent flyers which inhabit open areas such as savannahs and forest canopies $[4,7,21]$. These traits altogether may reflect in their expressive dispersal rate $(50 \%)$, as reported here. Moreover, large-bodied butterflies had a greater proportion of dispersing individuals which dispersed over longer distances, and were detected through longer periods, than their smaller relatives. 
(a)

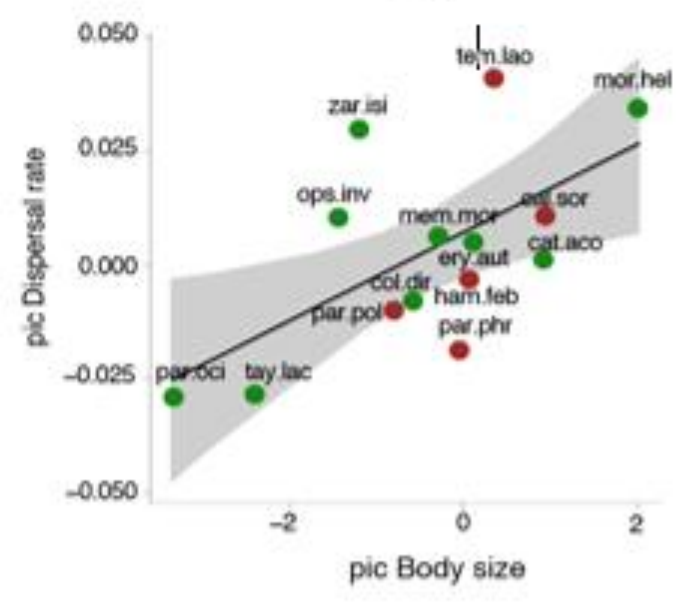

(b)

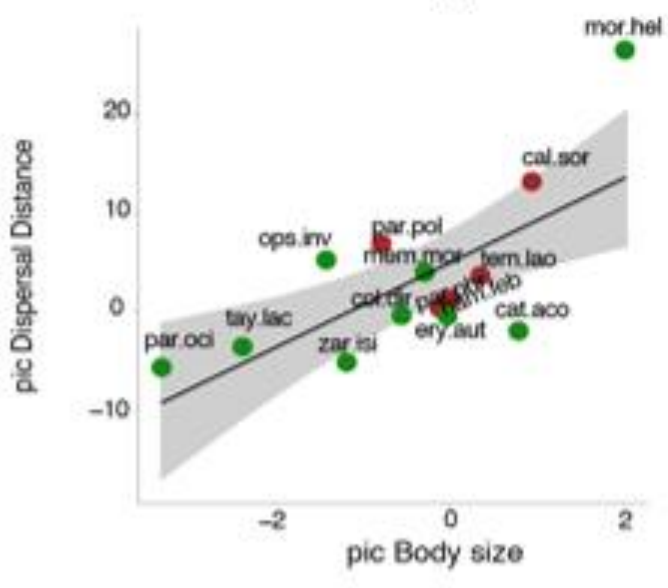

(c)

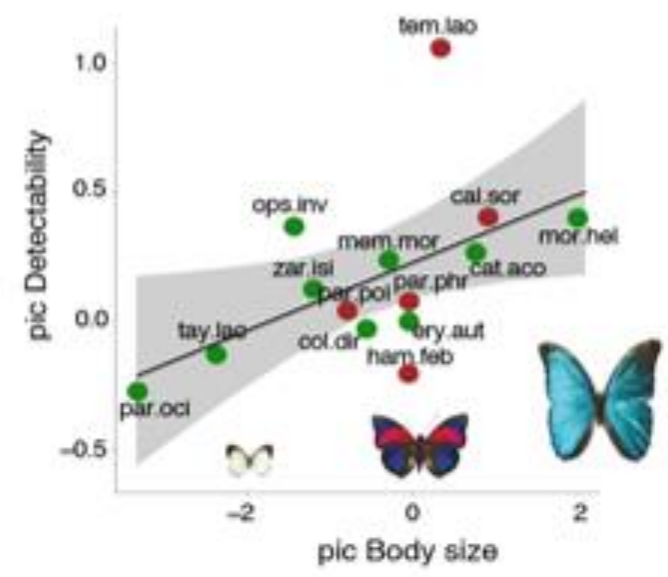

Figure 2. Phylogenetic independent contrasts' (PIC) results for the associations between body size and: (a) dispersal rate; (b) dispersal distance; and (c) individual detectability in fruit-feeding butterflies captured in 35 days in the Cerrado of Fazenda Água Limpa, Brasília, Brazil. Green circles represent the forest specialist species, while savannah specialist species are represented by the red circles.

Larger butterflies demand more resources, which may be forcing them to disperse in search for more suitable habitats [2]. On the other hand, smaller species may be better able to survive in small patches, reflecting in their lower dispersal ability [2]. If true, the patchy distribution of small-bodied species, if not compensated by their larger population sizes, should constrain their persistence in environments with intense deforestation, such as the Cerrado. Nevertheless, futher studies are required to assess the causal mechanisms operating to generate the observed patterns, and to test the correlates between the fine scale movements and large scale dispersal. Moreover, we highlights the importance to consider species evolutionary history in order to study complex trait-environment relationships.

\section{Conclusions}

Body size was a phylogenetically constrained trait and should be taken into account in further researches about trait-dispersal relationship. Clades composed by large-bodied butterflies had greater proportion of dispersing individuals which dispersed over longer distances, and were detected through longer periods than their smaller relatives. 
Author Contributions: G.B.F.J., I.R.D., and O.J.M.-F. conceived and designed the experiments, and have edited the manuscript; T.S., J.P.D., and. H.P. performed the experiments; G.B.F.J. analyzed the data; J.P.S., and A.V.L.F. contributed with phylogenetic analysis; G.B.F.J., and H.O. wrote the paper. All authors have read and agreed to the published version of the manuscript.

\section{Institutional Review Board Statement:}

\section{Informed Consent Statement:}

Data Availability Statement:

Acknowledgments: All sources of funding of the study should be disclosed. Please clearly indicate grants that you have received in support of your research work. Clearly state if you received funds for covering the costs to publish in open access.

Conflicts of Interest: The authors declare no conflict of interest.

\section{Abbreviations}

The following abbreviations are used in this manuscript:

MDPI Multidisciplinary Digital Publishing Institute

DOAJ Directory of open access journals

TLA Three letter acronym

LD linear dichroism

\section{Appendix A}

Table A1. Forewing length (mm); abundance (n); dispersal distance (m); dispersal rate (\%); and detectability (days) of fruit-feeding butterflies species captured in 35 consecutive days at Fazenda Água Limpa, Brasília, Brazil.

\begin{tabular}{|c|c|c|c|c|c|}
\hline Subfamily-Tribe/Species & Size-mm & $\mathbf{N}$ & $\begin{array}{c}\text { Dist-m } \\
\max (\text { mean } \pm \mathrm{sd})\end{array}$ & $\begin{array}{c}\text { Disp. Rate } \\
(\%)\end{array}$ & $\begin{array}{c}\text { Detec-days } \\
\max (\text { mean } \pm \mathrm{sd})\end{array}$ \\
\hline Biblidinae & $30.5 \pm 4.4$ & 179 & $356.1(50.7 \pm 72.5)$ & 0.3 & $26(5.8 \pm 7.1)$ \\
\hline Callicore sorana (Godart, [1824]) & $26.9 \pm 1.6$ & 16 & $123.1(24.6 \pm 48.3)$ & 0.3 & $6(3.5 \pm 3.6)$ \\
\hline Catagramma pygas (Godart, [1824]) & $26.01 \pm 1.4$ & 4 & - & - & - \\
\hline Catonephele acontius (Hübner, [1823]) & $32.9 \pm 2.6$ & 24 & $356.1(140.5 \pm 56.7)$ & 0.3 & $26(6.3 \pm 6.3)$ \\
\hline Hamadryas amphinome (Linnaeus, 1767) & $39.01 \pm 2.1$ & 1 & & - & - \\
\hline Hamadryas februa (Hübner, [1823]) & $33.4 \pm 1.2$ & 38 & $341.1(55.8 \pm 54.8)$ & 0.2 & $22(5.5 \pm 5.9)$ \\
\hline Hamadryas feronia (Linnaeus, 1758) & $34.7 \pm 2.1$ & 70 & $266.2(69.0 \pm 88.7)$ & 0.4 & $11(5.5 \pm 6.3)$ \\
\hline Temenis laothoe (Cramer, 1777) & $24.7 \pm 1.6$ & 25 & $157.1(54.7 \pm 49.1)$ & 0.3 & $20(3.2 \pm 4.3)$ \\
\hline Temenis huebneri (Fruhstorfer, 1907) & $24.7 \pm 1.3$ & 1 & - & - & - \\
\hline Charaxinae & $28.1 \pm 1.6$ & 14 & $105.1(47.8 \pm 38.3)$ & 0.55 & $17(5.1 \pm 5.9)$ \\
\hline Archaeoprepona demophon (Hübner, [1814]) & $46.3 \pm 1.4$ & 2 & - & - & - \\
\hline Memphis moruus (Fabricius, 1775) & $27.7 \pm 1.4$ & 6 & $105.1(50.6 \pm 47.3)$ & 0.5 & $17(4.2 \pm 4.5)$ \\
\hline Prepona claudina (Godart, [1824]) & $41.01 \pm 1.4$ & 1 & - & - & - \\
\hline Zaretis isidora (Cramer, 1777) & $28.6 \pm 1.6$ & 5 & $69.1(43.5 \pm 33.5)$ & 0.6 & $11(2.3 \pm 2.9)$ \\
\hline Nymphalinae & - & 14 & - & - & - \\
\hline
\end{tabular}




\begin{tabular}{|c|c|c|c|c|c|}
\hline Colobura dirce (Linnaeus, 1758) & $29.5 \pm 2.3$ & 12 & $183.2(75.8 \pm 76.3)$ & 0.3 & $10(3.5 \pm 3.5)$ \\
\hline Smyrna blomfildia (Fabricius, 1781) & $40.01 \pm 2.3$ & 1 & - & - & - \\
\hline Tigridia acesta (Linnaeus, 1758) & $22.01 \pm 2.3$ & 1 & - & - & - \\
\hline Satyrinae-Brassolini & $52.6 \pm 11.8$ & 23 & $422(124.7 \pm 142.1)$ & 0.36 & $17(3.8 \pm 4.9)$ \\
\hline Caligo illioneus (Cramer, 1775) & $65.9 \pm 4.0$ & 10 & $75.6(60.4 \pm 21.4)$ & 0.2 & $5(3.2 \pm 3.7)$ \\
\hline Catoblepia berecynthia (Cramer, 1777) & $41.01 \pm 2.2$ & 3 & - & - & - \\
\hline $\begin{array}{l}\text { Eryphanis automedon (C. Felder \& R. Felder, } \\
\text { 1867) }\end{array}$ & $53.9 \pm 2.2$ & 5 & $422.8(237.3 \pm 160.8)$ & 0.6 & $17(4.8 \pm 4.6)$ \\
\hline Opsiphanes invirae (Hübner, [1808]) & $38.1 \pm 2.0$ & 5 & $40.2(30.1 \pm 12.5)$ & 0.3 & $12(3.2 \pm 3.5)$ \\
\hline & & & & & continue \\
\hline Subfamily-Tribe/ Species & Size & $\mathrm{N}$ & $\begin{array}{c}\text { Dist-m } \\
\max (\text { mean } \pm \mathrm{sd})\end{array}$ & $\begin{array}{l}\text { Disp. rate } \\
(\%)\end{array}$ & $\begin{array}{c}\text { Detec-days } \\
\max (\text { mean } \pm \mathrm{sd})\end{array}$ \\
\hline Satyrinae-Morphini & - & 27 & - & - & - \\
\hline Morpho helenor (C. Felder \& R. Felder, 1867) & $59.1 \pm 4.1$ & 27 & $142.8(86.5 \pm 44.6)$ & 0.3 & $10(3.1 \pm 3.4)$ \\
\hline Satyrinae-Satyrini & $22.3 \pm 7.1$ & 282 & $272.1(49.2 \pm 53.3)$ & 0.15 & $21(2.3 \pm 3.1)$ \\
\hline Fosterinaria quantius (Godart, [1824]) & $23.1 \pm 0.8$ & 20 & - & - & - \\
\hline Pareuptychia ocirrhoe (Fabricius, 1776) & $19.9 \pm 1.4$ & 174 & $151.9(41.7 \pm 38.5)$ & 0.1 & $18(3.4 \pm 4.3)$ \\
\hline Paryphthimoides phronius (Godart, [1824]) & $19.7 \pm 1.1$ & 47 & $272.1(100.9 \pm 78.7)$ & 0.1 & $21(3.3 \pm 4.6)$ \\
\hline Paryphthimoides poltys (Prittwitz, 1865) & $20.2 \pm 0.8$ & 17 & $111.2(45.1 \pm 29.5)$ & 0.1 & $13(2.5 \pm 3.2)$ \\
\hline Taygetis virgilia (Cramer, 1776) & $36.01 \pm 1.6$ & 10 & - & - & - \\
\hline Taygetis laches (Fabricius, 1793) & $35.7 \pm 1.4$ & 10 & $171.1(66.9 \pm 52.1)$ & 0.3 & $8(2.1 \pm 2.6)$ \\
\hline Taygetis mermeria (Cramer, 1776 ) & $30.01 \pm 1.4$ & 4 & - & - & - \\
\hline Total & - & 539 & - & - & - \\
\hline
\end{tabular}

\section{References}

1. Phillips, B.L.; Brown, G.P; Shine, R. Evolutionarily accelerated invasions: the rate of dispersal evolves upwards during the range advance of cane toads. J. Evol. Biol 2010, 23, 2595-2601.

2. Stevens, V.M.; Trochet, A.; Dyck, H.V.; Colbert, J.; Baguete, M. How is dispersal integrated in life histories: Aquantitative analysis using butterflies. Ecol. Lett. 2012, 15, 74-86.

3. Fountain-Jones, N.M.; Baker, S.C.; Jordan, G.J. Moving beyond the guild concept: developing a practical functional trait framework for terrestrial beetles. Ecol. Entomol. 2015, 40, 1-13.

4. Spaniol, R.L.; Duarte, L.S.; Mendonça, M.S., Jr.; Iserhard, C.A. Combining functional traits and phylogeny to disentangling Amazonian butterfly assemblages on anthropogenic gradients. Ecosphere 2019, 10, e02837. doi:10.1002/ecs2.2837.

5. Faleiro, F.; Machado, R.B.; Loyola, R.D. Defining spatial conservation priorities in the face of land-use and climate change. Biol. Conserv. 2013, 158, 248-257.

6. Brown, J.H.; Gillooly, J.F.; Allen, A.P.; Savage, V.M.; West, G.B. Toward a metabolic theory of ecology. Ecology 2004, 85, 17711789.

7. Marini-Filho, O.J.; Martins, R.P. Nymphalid butterfly dispersal among forest fragments at Serra da Canastra National Park, Brazil. J. Insect Conserv. 2010, 14, 401-411. 
8. Gillespie, M.A.K.; Birkemoe, T.; Sverdrup-Thygeson, A. Interactions between body size, abundance, seasonality and phenology in forest beetles. Ecol. Evol. 2017, 7, 1091-1100.

9. Molleman, F.; Zwaan, B.J.; Brakefield, P.M.; Carey, J.R. Extraordinary long life spans in fruit-feeding butterflies can provide window on ecolution of life span and aging. Exp. Gerontol. 2007, 42, 472-482.

10. White, E.P.; Ernest, S.K.M.; Kerkhoff, A.J.; Enquist, B.J. Relationships between body size and abundance in ecology. Trends Ecol. Evol. 2007, 22, 323-330.

11. Ribeiro, D.B.; Freitas, A.V.L. Large-sized insects show stronger seasonality than small-sized ones: a case study of fruit-feeding butterflies. Biol. J. Linn. Soc. 2011, 104, 820-827.

12. Uehara-Prado, M.; Brown, K.S., Jr.; Freitas, A.V.L. Species richness, composition and abundance of fruit-feeding butterflies in the Brazilian Atlantic Forest: comparison between a fragmented and a continuous landscape. Glob. Ecol. Biogeogr. 2007, 16, 4354.

13. Shahabuddin, G.; Ponte, C.A. Frugivorous butterfly species in tropical forest fragments: correlates of vulnerability to extinction. Biodivvers. Conserv. 2005, 14, 1137-1152.

14. Skórka, P.; Kudlek, J.; Pepkowska, A.; Sliwinska, E.B.; Settele, J.; Woyciechowski, M. Movements and flight morphology in the endangered large blue butterflies. C Eur. J. Biol. 2013, 7, 662-669.

15. Pavoine, S.; Baguette, M.; Stevens, V.M.; Leibold, M.A.; Turlure, C.; Bonsall, M.B. Life history traits, but not phylogeny, drive compositional patterns in a butterfly metacommunity. Ecology 2014, 95, 3304-3313.

16. Duarte, L.D.S.; Debastiani, V.J.; Carlucci, M.B.; Diniz-Filho, J.A.F. Analyzing community- weighted trait means across environmental gradients: Should phylogeny stay or should it go? Ecology 2014, 99, 385-398.

17. Iserhard, C.A.; Duarte, L.; Seraphim, N.; Freitas, A.V.L. How urbanization affects multiple dimensions of biodiversity in tropical butterfly assemblages. Biodivvers. Conserv. 2019. doi:10.1007/s10531-018-1678-8

18. Graça, M.B.; Pequeno, P.A.C.L.; Frankling, E.; Morais, J.W. Coevolution between flight morphology, vertical stratification and sexual dimorphism: What can we learn from tropical butterflies? J. Evol. Biol. 2017, 30, 1862-1871.

19. Santos, A.C.; Sales, P.C.L.; Ribeiro, D.B. Habitat conversion affects beta diversity in frugivorous butterfly assemblages. Stud. Neotropical Fauna Environ. 2020, 55, 180-192.

20. Lourenço, G.M.; Soares, G.R.; Santos, T.P.; Dáttilo, W.; Freitas, A.V.L.; Ribeiro, S.P. Equal but different: Natural ecotones are dissimilar to anthropic edges. PLoS ONE 2019. doi:10.1371/journal.pone.0213008.

21. Freire, G.B.F., Jr.; Diniz, I.R. Temporal dynamics of fruit-feeding butterflies (Lepidoptera: Nymphalidae) in two habitats in a Brazilian environment. Fla. Entomol. 2015, 98, 1207-1216.

22. Espírito-Santo, M.M.; Leite, M.E.; Silva, J.O.; Barbosa, R.S.; Rocha, A.M.; Anaya, F.C.; Dupin, M.G.V. Understanding patterns of land-cover change in the Brazilian Cerrado from 2000 to 2015. Philos Trans. R. Soc. B 2016, doi:10.1098/rstb.2015.0435.

23. Colli, G.R.; Vieira, C.R.; Dianese, J.C. Biodiversity and conservation of the Cerrado: recent advances and old challenges. Biod. Conserv. 2020, 29, 1465-1475. doi:10.1007/s10531-020-01967-x.

24. Fonseca, M.S.; Silva-Júnior, M.C. Fitossociologia e similaridade florística entre trechos de Cerrado sentido restrito em interflúvio e em vale no Jardim Botânico de Brasília, DF. Acta Bot. Bras. 2004, 18, 19-29.

25. Freitas, A.V.L.; Iserhard, C.A.; Santos, J.P.; Carreira, J.Y.O.; Ribeiro, D.B.; Melo, D.H.A.; Rosa, A.H.B.; Marini-Filho, O.J.; Accacio, G.M.; Uehara-Prado, M. Studies with butterfly bait traps: An overview. Revista Colombiana de Entomología 2014, 40, $209-218$.

26. Brown, K.S., Jr. Geological, evolutionary and ecological bases of the diversification of Neotropical butterflies: implications for conservation. In Tropical Rainforests: Past, Present and Future; Bermingham, E., Dick, C.W., Moritz, C., Eds.; University of Chicago Press: Chicago, IL, USA, 2005; p. 672.

27. Revell, L.J. Phytools: An R package for phylogenetic comparative biology (and other things). Methods Ecol. Evol. 2012, 3, 217223. doi:10.1111/j.2041-210X.2011.00169.x.

28. Wahlberg, N.; Kodandaramaiah, J.U.; Pena, C.; Nylin, S.; Freitas, A.V.L.; Brower, A.V.Z. Nymphalid butterflies diversify following near demise at the Cretaceous/Tertiary boundary. Proc. Biol. Sci. 2009, 276, 4295-4302.

29. Schneider, C.A.; Rasband, W.S.; Eliceiri, K.W. NIH image to ImageJ: 25 years of image analysis. Nat. Methods 2012, 9, 671-675.

30. Garland, T.; Harvey, P.H.; Ives, A.R. 1992. Procedures for the analysis of comparative data using phylogenetically independent contrasts. Syst. Biol. 1992, 1, 18-32.

31. Blomberg, S.P.; Garland, T.; Ives, A.R. Testing for phylogenetic signal in comparative data: Behavioral traits are more labile. Evolution 2013, 57, 717-745.

32. Paradis, E.; Schliep, K. ape 5.0: an environment for modern phylogenetics and evolutionary analyses in R. Bioinformatics 2019, 35, 526-528. doi:10.1093/bioinformatics/bty633.

33. Legendre, P.; Desdevises, Y. Independent contrasts and regression through the origin. J. Theor. Biol 2009, 259, 727-743.

34. Kembel, S.; Cowan, P.D.; Helmus, M.R.; Cornwell, W.K.; Morlon, H.; Ackerly, D.D.; Webb, C.O. Picante: R tools for integrating phylogenies and ecology. Bioinformatics 2010, 26, 1463-1464.

35. Ravell, L.J. Phytools: An R package for phylogenetic comparative biology (and other things). Methods Ecol. Evol. 2012, 3, 217223. doi:10.111/j.2041-210X.2011.00169.x. 